\section{Eleiçóes como o milagre da democracia. Ainda}

\section{Elections as democracy's wonder. Still}

PRZEWORSKI, Adam. Why bother with elections? Cambridge: Polity Press, 2018. E-book.

\section{Nara Salles (1) \\ https://orcid.org/0000-0002-2681-8412}

(1) Instituto de Estudos Sociais e Políticos (IESP/UERJ), Rio de Janeiro, RJ, Brasil. E-mail: narasal@iesp.uerj.br.

DOI $10.1590 / 3510416 / 20$

Resenha recebida em: 08/09/2019

Aprovada em: 20/12/2019

Vitórias de líderes autoritários, como Donald Trump, nos Estados Unidos, Viktor Orbán, na Hungria, e Jair Bolsonaro, no Brasil, têm suscitado diagnósticos crescentes de colapso das democracias. Foa \& Mounk (2016), por exemplo, relacionam esse fenômeno às mudanças nos meios de comunicação, à estagnação econômica e a questôes identitárias. Levitsky \& Ziblatt (2008), por sua vez, se voltam para a erosão das regras democráticas, formais e informais, por seus agentes. Em comum, há a preocupação de que o retrocesso democrático já não se apresenta mais na forma clássica dos golpes de Estado, mas por meio das urnas.

Em obra recente, Adam Przeworski se distancia de tais conclusóes, que caracteriza como declaraçóes para atrair manchetes de jornal, como afirmou em entrevista à Folha de S. Paulo. ${ }^{1}$ Para o autor, a eleição de líderes autoritários ou a ascensão de partidos anti-establishment na Europa não devem ser tratados como fenômenos intrinsecamente antidemocráticos. Afinal, o êxito de projetos dos quais se discorda não deve ser interpretado como uma crise da democracia, mas como o funcionamento de um sistema que intercala fracassos e esperanças a cada ciclo eleitoral. No entanto, ele alerta: "[...] também não devemos ser otimistas. Algo profundo está acontecendo”. ${ }^{2}$ (p. 112).

Para Przeworski, e não apenas nesta obra, a relevância dos processos eletivos é evidente: processar conflitos pacificamente. Desde sua clássica análise do socialismo eleitoral na Europa Ocidental, o autor já havia apontado a necessidade de se obedecer à lógica eleitoral, em vez de iniciativas insurreicionistas. As barricadas, então, teriam dado lugar às urnas, de modo que o voto se constituiu como pedras de papel (Przeworski e Sprague, 1986). Esse é, no fim, o milagre da democracia przeworskiana: a substituição das armas pelo voto, pedras de papel, na regulaçáo dos conflitos sociais. Há competição, há vencedores, mas também regras e perdedores, que aguardam novas rodadas do jogo. Em suas palavras,

a política, em qualquer forma ou configuração, tem limites para moldar e transformar as sociedades. Isso é apenas um fato da vida. Acredito que é importante reconhecer esses limites para não criticar as eleiçôes por não alcançarem o que nenhum arranjo político poderia alcançar (p. 12) ${ }^{3}$.

O problema é que este milagre não é inabalável, mas varia em função de diversas condiçóes. No cenário contemporâneo, as eleiçóes deverão persistir enquanto milagre da democracia? É sobre esses limites e condiçóes que Przeworski se debruça nesta contribuição recente.

$\mathrm{Na}$ primeira parte da obra, o autor discute o funcionamento das eleiçóes, destacando três aspectos principais: a ideia de escolher governos; a proteção da propriedade; e as disputas partidárias. $\mathrm{Na}$ segunda, volta sua atenção para aquilo que as eleiçôes podem ou não alcançar. Aqui, o debate gira em torno de racionalidade e divergência e convergência de interesses; representação e mecanismos de controle e accountability, com ênfase no papel da burocracia; performance econômica; relação entre os processos eletivos e igualdade econômica e social; e paz civil.

Em um retorno a Rousseau, Przeworski parte da relação entre representação e eleiçóes, fundamentada na autorização que o povo, usando sua legitimidade exclusiva, concede a qualquer exercício de poder sobre si mesmo. Apenas por meio dessa unidade entre governantes e governados o dilema entre liberdade e coaçáo pode ser solucionado: concordamos em ser coagidos porque escolhemos quem irá nos coagir e como. Assim, "as pessoas são livres porque podem escolher seus governantes" ${ }^{4}$ (p. 20). A verdade, 
porém, é que, na prática, a qualquer momento da vida política de qualquer sociedade, algumas pessoas sempre dominam as demais, disfarçando o mito do autogoverno por intermédio das eleiçóes.

O diálogo direto que Przeworski traça com Manin (1997) reforça o caráter necessariamente desigual das eleiçóes, já que o ato de escolher exige distinção ou, em outras palavras, o reconhecimento de diferentes capacidades de governar. Assim, se todos fossem igualmente virtuosos e capazes de governar, o fariam da mesma maneira. A necessidade de uma escolha, no entanto, reflete o fato de que alguns são considerados melhores ou mais adequados que outros. O resultado é a natureza aristocrática das eleiçóes, e a concorrência entre representantes potenciais que são socialmente distintos de seus eleitores.

Se, inicialmente, o status social foi um determinante de capacidade maior de representação, essa associação foi enfraquecida com o advento das organizaçôes populares da classe trabalhadora. A escolha, agora, passa a ser entre concorrentes que, organizados em partidos, propóem plataformas. Ainda assim subjaz, aqui, a ideia de que algumas pessoas são mais qualificadas para a representação do que outras, embora eleiçóes livres impliquem que cada eleitor possa decidir quais qualidades são mais relevantes e quais são os indicadores observáveis delas (p. 23).

Os padróes históricos em diferentes períodos e países recuperados pelo autor fundamentam o argumento de que as eleiçóes têm pouca capacidade de transformar a economia e as relaçóes sociais. O processo narrado por Przeworski evidencia a rápida expansão das eleiçóes, simultânea ao processo duradouro que restringe os direitos políticos às classes altas. Transformaçóes, ao longo do tempo, garantiram o sufrágio universal e eleiçóes, em geral, diretas e secretas, além de legislaturas mais frequentemente unicamerais. Apesar disso, o uso do poder de veto do executivo não diminuiu, e reformas constitucionais e independência dos bancos centrais se tornaram mais universais. Tem-se, assim, um ciclo recorrente de concessões, reversóes e substituição de mecanismos protetores dos interesses das elites.

Quando essas elites são os partidos, dispostos na competição eleitoral, o mecanismo clássico consiste em eleitores livres, e politicamente iguais, escolhendo governos por plataformas e candidatos. Przeworksi, no entanto, opóe esse cenário ao fato histórico de que titulares de cargos públicos raramente são derrotados, apontando que há mais nas eleições do que a livre escolha dos eleitores. Para ele, os acontecimentos no dia da votação não apenas resultam de longos processos que envolvem persuasão, manipulação e repressão, como podem implicar, ainda, intimidação e fraude. O pós-eleitoral, portanto, nem sempre condiz com o resultado anunciado: é preciso reconhecer a derrota.

A oposição é retratada como questão crucial na organização de qualquer ordem política. Se, até o fim da Primeira Guerra Mundial, a luta girava em torno da extensão do sufrágio, a principal demanda durante o século XX foi o direito de organizar e contestar as eleiçóes. Ele salienta: "O direito de se opor é uma conquista. Ele é um direito fraco e reversível"5 (p. 49). Especificamente por isso, persistem divergências quanto à lealdade e ao caráter subversivo da oposição, seus mecanismos institucionais, direitos de associaçáo, protestos e desobediência civil. Como os governantes querem manter seu poder, podem tentar impor obstáculos à formação e à atuação da oposição. Mas não descaradamente, argumenta Przeworski. É preciso estabelecer um equilíbrio - delicado, porém imprescindível - entre limitar a oposição e preservar a crença de que as pessoas podem escolher.

Há uma série de instrumentos para a manutenção do poder à disposição dos incumbentes. $\mathrm{O}$ primeiro fator que recebe a atenção do autor é a manipulação das regras eleitorais, como os locais e dias da votação, por exemplo. A regulamentação das eleições afeta seus resultados e é promulgada de forma endógena por maiorias, o que permite a Przeworski afirmar que são “inextricavelmente manipuladas" (p. 50). Se os titulares, então, possuem maiorias, podem facilmente usar tais regras a seu favor. O uso partidário do aparato estatal é outro mecanismo potencialmente vantajoso para os que estão no poder. Mesmo que políticos eleitos não implementem as decisões públicas, a burocracia estatal pode funcionar com fins partidários e eleitorais.

O terceiro item elencado por Przeworski é a repressão, ou o uso da força, para reprimir a oposição, seja impedindo sua organização e participação eleitoral ou excluindo suas ideias da esfera pública. Em seguida, o autor retoma a temática do financiamento 
eleitoral - afinal, "política custa dinheiro"6 (p. 56). Embora essa perniciosa relação não seja prerrogativa dos incumbentes, eles têm mais probabilidade de arrecadaçấo maior. Por fim, como último recurso, Przeworski insere a fraude, com uma distinção fundamental: manipulação consiste em definir regras favoráveis, e fraude, em violar as regras existentes, por mais tendenciosas que sejam.

Todos esses fatores se relacionam à competividade das eleiçôes. Para Przeworski, elas são competitivas quando os eleitores de fato escolhem quem vence e, mais importante, quando têm a possibilidade de trocar quem está no poder. Apesar disso, elas nunca são justas, porque devem ser conduzidas por alguma regra e, qualquer que seja esta regra, ela influenciará as chances de algum modo. Eleiçôes também não são absolutamente "limpas", já que nâo há como impedir o uso de truques que resultem em vantagens eleitorais. Ainda assim, desde que haja incerteza em meio às chances desiguais, e que os partidos influenciem somente a sua probabilidade de sua vitória, as eleiçóes são competitivas.

Ao longo da obra, Przeworski apresenta as características dos processos eleitorais, construindo o argumento de que eleiçóes não são perfeitas:

Embora os políticos tenham que fingir ser inspiradores, alegando que seus ideais elevados nos levarão a um futuro radiante, eles usam todos os meios para vencer. Eles postulam, enganam e iludem. Fazem promessas que sabem ser inviáveis, gastam grande parte de suas energias difamando um ao outro, mexem nas regras quando podem e evitam-nas quando nấo podem, e tentam silenciar a voz das pessoas que podem se opor a elas (p. 66) ${ }^{7}$.

Todavia, nem todas as queixas dirigidas comumente às eleiçôes são justas. Um exemplo é que elas não oferecem opçóes reais ao eleitorado, tratando-se de uma escolha nos moldes "Coca-Cola ou Pepsi"; contra ele, Przeworski argumenta que, se um conjunto similar de políticas é oferecido, é porque os partidos acreditam que esta é a preferência dos eleitores. Desse modo, enquanto sociedade, há, sim, uma escolha. No fim, valorizamos as eleiçôes porque são nossa segunda melhor opção: na impossibilidade de fazer o que queremos, e na necessidade de ser governados, decidir por quem e como é o que nos resta.

A forma como cada um toma sua decisão varia em função de crenças e interesses. Por mais que os processos de deliberação possam trazer justificativas, esclarecimentos e orientaçóes para as escolhas, sua autorização se origina no voto, e não na discussão. Eleiçōes são decididas assim, e não por razóes, defende Przeworski. Ademais, todos devem ser tratados como os melhores juízes de seus próprios interesses; eis o princípio fundamental do liberalismo (p. 68). No entanto, há a crença de algo compartilhado a ser perseguido e promovido - "res publica", "bem comum", "interesse público".

Esse ideal de consenso, unidade e harmonia oferecem, para o autor, a perspectiva de que regras processuais são capazes de construir um mundo mais justo e racional. Todavia, a preferência da maioria nada mais é do que a expressão da vontade do maior número de pessoas, e não daquilo que possuem em comum. Disso resulta que, inevitavelmente, alguns sempre perdem, enquanto outros sempre ganham, independentemente das açóes que o governo escolher. É nessa estrutura subjacente de interesses que reside a racionalidade das decisões governamentais. Quando as escolhas individuais são harmoniosas a ponto de originar um interesse coletivo, o voto gera, segundo Przeworski, decisôes racionais. Quando os valores estấo em conflito, por sua vez, o máximo que se pode afirmar é se o governo atende ou não à vontade da maioria (pp. 71-72). Desse ponto de vista, a questão se torna, então, minimizar a insatisfação coletiva.

Questionando se podemos esperar que os governos eleitos representem efetivamente a maioria, o autor aborda o voto como importante ferramenta de accountability e controle. Contudo, para que ele possa de fato ser uma ameaça à permanência dos eleitos, a informação é imprescindível. Apenas de posse dela os eleitores podem julgar se os governos agem ou náo conforme seus interesses, e sancioná-los ou premiá-los adequadamente. Przeworski distingue, assim, dois tipos de controle das eleiçóes sobre a representação: prospectivo e retrospectivo. No primeiro, os eleitores são orientados por plataformas apresentadas durante as campanhas, que expóem quais políticas serão 
implementadas no futuro. Retrospectivamente, a avaliação é feita com relação a políticas já executadas.

Dois desafios se colocam ao controle dos cidadãos sobre o governo. Primeiramente, com informação limitada e conhecimento restrito das consequências, governos costumam sempre reivindicar crédito em açôes bem-sucedidas, e se eximir dele, em situaçóes de fracasso. Ao eleitorado cabe decidir em que acreditar. Nesse sentido, Przeworski ressalta a importância das personalidades enquanto proxy de ações no cargo. Aqui, a questáo da multidimensionalidade da disputa também é retomada: os governos adotam muitas políticas, mas os eleitores possuem apenas um voto. Portanto, ainda que tivessem informação completa, eles precisariam definir quais as áreas de maior saliência para a tomada de decisão. A burocracia consiste no segundo revés ao processo de controle, já que os eleitos não executam diretamente os serviços públicos. Nas palavras do autor, "pode ser por isso que as pessoas se sentem politicamente ineficazes: não porque o voto não tem eficácia causal, mas porque as eleições são um mecanismo altamente indireto de controle sobre as burocracias públicas"8 (p. 81).

A insatisfação com as eleiçóes, mencionada de forma recorrente nas teses sobre crise da democracia, se relaciona também com a estagnação econômica e com os altos índices de desemprego. Nesse cenário, há, para Przeworski, uma mudança histórica de expectativas: agora, muitas pessoas já não acreditam que seus filhos terão uma vida melhor do que a sua. A partir da experiência estadunidense, ele ressalta que as consequências políticas dessa erosão da crença no progresso geracional são ameaçadoras. Esses resultados não se originam apenas das performances dos governos; também se relacionam com o arcabouço institucional de cada país.

Embora identificar os efeitos de economia e instituiçóes seja a velha história do ovo e da galinha, a única conclusão do autor é que as autocracias não apresentam melhor desempenho econômico do que os sistemas eleitorais realmente competitivos. Se as democracias crescem mais rapidamente, ou se não há diferença entres esses regimes, são perguntas ainda em aberto. Mesmo assim, Przeworski elenca que, nas democracias, há menor taxa de mortalidade infantil, maior expectativa de vida, salários mais altos e menor volatilidade econômica. Isso não significa, porém, que as eleiçóes resultem em igualdade econômica e social.

Mesmo que seja difícil compreender a coexistência do sufrágio universal com a desigualdade econômica, os dados levantados pelo autor mostram que eleiçóes competitivas não produzem reduçâo da desigualdade. Mais do que isso: governos democráticos redistribuem mais renda à medida que a desigualdade passa de níveis muito baixos para intermediários, e redistribuem menos quando ela já é alta. Não é que Przeworski negue explicações comuns para esses fenômenos, como o maior impacto de clivagens religiosas, as expectativas de mobilidade social ou o interesse na manutenção do status quo pela classe média. Para ele, porém, isso se justifica pelo simples fato de que as pessoas não são politicamente iguais em sociedades economicamente desiguais (p. 87).

Quando entram no domínio da política, como cidadãos, os indivíduos se tornam anônimos. [...] Mas isso não significa que eles se tornaram repentinamente iguais. Como indivíduos, eles permanecem ricos ou pobres, educados ou não. Eles continuam dotados de recursos desiguais (p. 88) $)^{9}$.

O ponto é que tais recursos acabam concedendo maior ou menor influência sobre os governos. A desigualdade econômica, portanto, resulta em desigualdade política que, por sua vez, inclina as políticas de forma favorável aos privilegiados, perpetuando a desigualdade econômica. Com esse círculo vicioso, Przeworski nos lembra que os mecanismos políticos estão inseridos nas sociedades, em seus mercados, divisões sociais, étnicas e religiosas, e estruturas de propriedade. Tais condições limitam o que qualquer sistema político pode alcançar; assim, não se pode esperar das eleições resultados que nenhum arranjo poderia obter.

Isso não significa que os governos sejam indiferentes. Ao contrário, a perspectiva de vencer a próxima rodada do jogo é o que permite que pessoas com preferências heterogêneas processem seus conflitos sem derramamento de sangue, embora nem sempre ofereçam bons governos, racionalidade, justiça, igualdade ou desenvolvimento. É especificamente 
essa capacidade de regular conflitos que constitui, para Przeworski, o milagre da democracia que ainda persiste. Portanto, ainda é cedo para dizer que a democracia está em crise. "Desejar que governos sejam eficientes, esperar que sejam competentes e eficazes para melhorar a vida das pessoas, não implica abdicar do direito de escolhê-los e substituí-los quando caem"10 (p. 104), afirma.

Przeworski não negligencia as transformações políticas que atingem diversos países, nem faz uma defesa cega do mecanismo eletivo. Pelo contrário: reconhece que a democracia nem sempre é capaz de reduzir as desigualdades econômicas; e que eleiçóes exigem superioridades, que nem sempre são justas e que podem até mesmo ser manipuladas. No entanto, para ele, elas permanecem sendo o mecanismo por excelência de regulação de conflitos sociais. São, portanto, não apenas equivocados, mas injustos os diagnósticos de colapsos democráticos.

Sua análise, em vez de privilegiar a agência de líderes autoritários, como em Foa \& Mounk (2016) e Levitsky \& Ziblatt (2008), chama a atenção para o intenso partidarismo baseado em partidos fracos e para o crescimento da polarização e da intensidade dos conflitos. Esses, se deixam os limites institucionais e se espalham no exterior da estrutura representativa, implicam, para os governos, apenas espirais de quebra da ordem e repressão. Esses ciclos podem impedir a implementação de políticas estáveis e, assim, acabar por minar a democracia. Por ora, no entanto, estejamos apenas atentos. As eleiçóes persistem como ciclos de decepção e esperança nos quais, apesar de todas as limitaçóes, ainda queremos apostar, e que ainda queremos defender.

\section{Notas}

1 Disponível em: <https://www1.folha.uol.com.br/ ilustrissima/2019/05/morte-da-democracia-viroubordao-para-atrair-imprensa-diz-autor.shtml>.

2 No original: "Although we should not be desperate, we should also not be sanguine. Something profound is going on". Todas as traduçóes presentes nesta resenha são da autora.
3 No original: "Politics, in any form or fashion, has limits in shaping and transforming societies. This is just a fact of life. I believe that it is important to know these limits, so as not to criticize elections for not achieving what no political arrangements can achieve".

4 No original: "People are free because they can choose their rulers".

5 No original: "The right to oppose is a conquest. It is feeble and reversible".

6 No original: "Politics costs money".

7 No original: "Elections are not pretty. While politicians have to pretend to be inspirational, claiming and that their lofty ideals will lead us to a radiant future, they use every hook or crook to win. They posture, monger, and deceive. They make promises they know to be infeasible, spend much of their energies smearing each other, tinker with rules then can and evade them when they cannot, and try to mute the voice of the people who may be opposed to them".

8 No original: "This may be why people feel politically ineffective: not because voting has no causal efficacy, but because elections are a highly indirect mechanism of control over public bureaucracies".

9 No original: "When they enter the realm of politics, as citizens, individuals become anonymous. [...] But this does not mean that they have suddenly become equal. As individuals they remain wealthy or poor, educated or not. They are still endowed with unequal resources".

10 No original: "Wanting governments to be effective, hoping that they will be competent and effective in improving people's lives, does not imply abdication from the right to choose them and to replace them when they fall".

\section{BIBLIOGRAFIA}

FOA, Roberto; MOUNK, Yascha. (2016), “The Democratic Disconnect". Journal of Democracy, 27, 6: 5-17.

LEVITSKY, Steven; ZIBLATT, Daniel. (2008), Como as democracias morrem. Rio de Janeiro: Zahar.

MANIN, Bernard. (1997), The Principles of Representative Government. Cambridge University Press.

PRZEWORSKI, Adam; SPRAGUE, John. (1986), Paper Stones: A History of Electoral Socialism. Chicago: The University of Chicago Press. 